\title{
Supraphysiological doses of performance enhancing anabolic-androgenic steroids exert direct toxic effects on neuron-like cells
}

\author{
John R. Basile ${ }^{1,2}$, Nada O. Binmadi ${ }^{1,3}$, Hua Zhou ${ }^{1}$, Ying-Hua Yang ${ }^{1}$, Antonio Paoli ${ }^{4}$ and Patrizia Proia ${ }^{1,5 *}$ \\ ${ }^{1}$ Department of Oncology and Diagnostic Sciences, University of Maryland Dental School, Baltimore, MD, USA \\ 2 Marlene and Stuart Greenebaum Cancer Center, University of Maryland, Baltimore, MD, USA \\ ${ }^{3}$ Department of Oral Basic and Clinical Sciences, King Abdulaziz University, Jeddah, Saudi Arabia \\ ${ }^{4}$ Department of Biomedical Sciences, University of Padova, Padova, Italy \\ ${ }^{5}$ Department of Sports Science (DISMOT), University of Palermo, Palermo, Italy
}

\section{Edited by:}

Chao Deng, University of

Wollongong, Australia

Reviewed by:

Agata Copani, University of Catania, Italy

Aram Megighian, University of

Padua, Italy

${ }^{*}$ Correspondence:

Patrizia Proia, Department of Sports Science (DISMOT), University of

Palermo, Via Eleonora Duse 2,

Palermo 90146, Italy.

e-mail: patrizia.proia@unipa.it
Anabolic-androgenic steroids (AAS) are lipophilic hormones often taken in excessive quantities by athletes and bodybuilders to enhance performance and increase muscle mass. AAS exert well known toxic effects on specific cell and tissue types and organ systems. The attention that androgen abuse has received lately should be used as an opportunity to educate both athletes and the general population regarding their adverse effects. Among numerous commercially available steroid hormones, very few have been specifically tested for direct neurotoxicity. We evaluated the effects of supraphysiological doses of methandienone and 17- $\alpha$-methyltestosterone on sympathetic-like neuron cells. Vitality and apoptotic effects were analyzed, and immunofluorescence staining and western blot performed. In this study, we demonstrate that exposure of supraphysiological doses of methandienone and 17- $\alpha$-methyltestosterone are toxic to the neuron-like differentiated pheochromocytoma cell line PC12, as confirmed by toxicity on neurite networks responding to nerve growth factor and the modulation of the survival and apoptosis-related proteins ERK, caspase-3, poly (ADP-ribose) polymerase and heat-shock protein 90. We observe, in contrast to some previous reports but in accordance with others, expression of the androgen receptor (AR) in neuron-like cells, which when inhibited mitigated the toxic effects of AAS tested, suggesting that the AR could be binding these steroid hormones to induce genomic effects. We also note elevated transcription of neuritin in treated cells, a neurotropic factor likely expressed in an attempt to resist neurotoxicity. Taken together, these results demonstrate that supraphysiological exposure to the AAS methandienone and 17- $\alpha$-methyltestosterone exert neurotoxic effects by an increase in the activity of the intrinsic apoptotic pathway and alterations in neurite networks.

\section{Keywords: anabolic-androgenic steroids, PC12, neurotoxicity, apoptosis, neuritin}

\section{INTRODUCTION}

Anabolic-androgenic steroids (AAS) are lipophilic hormones, derived from cholesterol, that include in the same family the natural male hormone testosterone, along with the related molecules methandienone, $17-\alpha$-methyltestosterone, nandrolone, and androsterone (Orlando et al., 2007). For many years athletes and bodybuilders have been taking AAS in supraphysiological doses in order to attain greatly increased muscle mass, well beyond what can be achieved through natural means (Kouri et al., 1995), without regards to their potentially toxic side effects. Intake of AAS by athletes and others in an attempt to gain strength and improve performance is often associated with toxic effects on the liver, the cardiovascular system and the

Abbreviations: AAS, anabolic-androgenic steroids; CNS, central nervous system; AR, androgen receptor; PARP, poly (adenosine diphosphate [ADP]-ribose) polymerase; Hsp, heat shock protein; NGF, nerve growth factor; PC12, pheochromocytoma 12 cells; EB, Ethidium bromide; AO, Acridine orange. male and female reproductive systems (Trifunovic et al., 1995; Basaria, 2010). At the physiological level, there are a wide range of effects of AAS as they possess both anabolic, or muscle-building, and androgenic, or masculinizing, properties (Kanayama et al., 2007). For example, while AAS use in women is generally uncommon, this population is highly vulnerable to the masculinizing effects of AAS and any resulting reproductive changes (Malarkey et al., 1991; Gruber and Pope, 2000; Kanayama et al., 2007). For these reasons, since 1999 the committee of the Word Antidoping Agency has been monitoring and regulating the use of AAS, along with similar compounds classified as nutritional supplements (http://www.wada-ama.org, The 2012 Prohibited List; and Carmo et al., 2011).

AAS exert their effects in many parts of the body, including the reproductive and endocrine tissues, muscle, bone, hair follicles in the skin, the liver and kidneys, and the hematopoietic, immune and central nervous systems (CNS) (Mooradian et al., 
1987). For example, experiments carried out on human umbilical vein endothelial cells to study the consequences of treatment with high concentrations of some AAS have revealed significant anti-proliferative effects, dramatically altered intracellular concentrations of calcium and induction of apoptosis (D'Ascenzo et al., 2007). A major concern regarding AAS is their influence on behavior, which is often correlated with stroke, mood disturbances, and psychotic symptoms (Uzych, 1992; Hall and Chapman, 2005; Santamarina et al., 2008). In vivo administration of high doses of androgens has been linked to neurobehavioral changes like hyperexcitability, heightened aggressive behavior, and suicidal tendencies (Tirassa et al., 1997; Thiblin et al., 2000). There is evidence that some of this behavior could be caused by the effects of AAS over synapse formation and function (Penatti et al., 2009, 2011; Oberlander and Henderson, 2012). However, particularly under conditions of high concentrations of testosterone and its metabolites, AAS may cause these changes as a result of functional, morphological and biochemical effects on neurons themselves, culminating in cell death (do Carmo et al., 2012).

Inappropriate activation of apoptosis in neurons has been associated with several neurological illnesses, including Huntington disease and Alzheimer disease (AD) (Varshney and Ehrlich, 2003; Tang et al., 2005). Non-physiological concentrations of AAS have been shown to induce neurotoxicity over a long time course when in the presence of $\beta$-amyloid, an important component of AD (Caraci et al., 2011). Most of the CNS effects are of psychiatric origin, and whether or not AAS are toxic to neurons is yet unknown. Orlando et al. studied the effect of some AAS on excitotoxic neuronal death induced by $\mathrm{N}$-methyl-d-aspartate (NMDA) in primary cultures of mouse cortical cells. Under these conditions, testosterone amplified excitotoxic neuronal death at high concentrations $(10 \mu \mathrm{M})$ (Orlando et al., 2007).

Given that AAS abuse poses a significant public health problem and based upon the previously published data, we investigated the morphological, biochemical and molecular mechanisms leading to changes in neuronal physiology, in particular neuronal cell death, for supraphysiological concentrations of methandienone and 17- $\alpha$-methyltestosterone, two AAS commonly found for sale on the internet and used for gain muscle mass but less studied than other hormones such as nandrolone and androsterone. Derivates of methandienone and 17- $\alpha$-methyltestosterone also resist metabolism in the liver and contain modifications that are associated with significant hepatic toxicities (Kuhn, 2002); of particular relevance, C17 $\alpha$-alkylated AAS, such as $17 \alpha$-methyltestosterone, cannot be aromatized to $17 \beta$-estradiol and can also inhibit aromatase activity. Supraphysiological levels of $17 \alpha$-methyltestosterone may promote diminished aromatization (and thus estrogen levels) by directly inhibiting the activity of this enzyme (Penatti et al., 2011).

There are a number of well characterized in vitro models that have been used to examine chemical effects on neurite outgrowth (Radio and Mundy, 2008). We chose to utilize the neuron-like PC12 cell model. PC12 are a line that has been widely employed in neurobiological investigations in order to evaluate the effects of different drugs and potentially neurotoxic compounds on cell morphology and physiology (Fujita et al., 1989; Vaudry et al., 2002; Radio and Mundy, 2008). Following exposure to nerve growth factor (NGF), PC12 cells differentiate into a sympatheticlike neuron and develop extensive neuritic processes (Greene and Rein, 1977), making this line an excellent model for evaluation of environmental compounds on neurite outgrowth and differentiation (Chan and Quik, 1993; Das and Barone, 1999; Lein et al., 2000; Crumpton et al., 2001; Parran et al., 2003).

Here we demonstrate that rat neurons and PC12 cells express the androgen receptor (AR). We describe a reduction in neurite networks and loss of survival signaling and enhanced apoptosis, as evidenced by a decrease in phospho-ERK and an increase in the levels of the active fragment of caspase 3 and cleaved poly (adenosine diphosphate [ADP]-ribose) polymerase (PARP), as well as upregulation and cleavage of heat shock protein (Hsp) 90, occurring in a dose-dependent manner in androgen treated PC12 differentiated in NGF. Many of these observations were noted after long exposures of PC12 to AAS, suggesting a genomic effect, and through the use of hydroxyflutamide we demonstrate that AAS toxicity proceeds directly through the AR, likely altering gene transcription to affect cell survival (Heinlein and Chang, 2002; Nguyen et al., 2007). However, we also observed a short-term increase in neuritin expression, an adaptive reaction seen in neurons in response to injury. Taken together, these results suggest that AAS may exert direct toxic effects on neurons of the CNS in those abusing these substances in athletic training.

\section{MATERIALS AND METHODS CELL CULTURE AND HORMONE TREATMENT}

Undifferentiated pheochromocytoma 12 cells (PC12, ATCC, Manassas, VA) were cultured in RPMI-1640 medium containing $10 \%$ horse serum and $5 \%$ fetal bovine serum (SigmaAldrich, St. Louis, MO). For induction of differentiation, cells were grown in 12-well plates on poly-D-lysine (Sigma-Aldrich) at an initial concentration of $1 \times 10^{5}$ cells per square centimeter in a medium supplemented with $200 \mathrm{ng} / \mathrm{ml}$ of nerve growth factor (NGF, Promega Corporation, Madison, WI) for 5 days. During this time, cells attached to the substratum and produced a network of neurites. Differentiated PC12 cultures were treated with vehicle (dimethyl ether, DME) or the steroid hormones androsterone, nandrolone, methandienone and 17- $\alpha$ methyltestosterone (Cerilliant Corporation, Round Rock, Texas) at a concentration of $50-75 \mu \mathrm{M}$ for times defined as short term $(24 \mathrm{~h})$, and long term (48 h) (Duranti et al., 2011), and preincubated for $2 \mathrm{~h}$ with vehicle control or $10 \mu \mathrm{M}$ hydroxyflutamide (Sigma-Aldrich, St. Louis, MO) (Nguyen et al., 2007) where indicated. Preliminary experiments verified that DME did not have any effects compared to an evaluation of untreated cells (data not shown).

\section{IMMUNOHISTOCHEMISTRY}

Immunohistochemistry on rat brain slices was performed following the protocol described previously (Basile et al., 2006). The primary antibody was anti-AR (Santa Cruz, CA). Images were acquired using a digital SPOT camera (SPOT Imaging Solutions, Sterling Heights, MI) attached to an inverted Nikon phase-contrast microscope (Nikon Instruments, Melville, NY). 


\section{IMMUNOCYTOCHEMISTRY}

Control or methandienone and 17- $\alpha$-methyltestosterone treated PC12 cells were fixed with $4 \%$ paraformaldehyde in PBS for $10 \mathrm{~min}$. on ice and subsequently permeabilized in cold methanol for an additional $5 \mathrm{~min}$. After three washes with PBS, cells were blocked with 5.5\% FBS in PBS with $0.1 \%$ Triton X-100 for $45 \mathrm{~min}$. at room temperature. The cells were then incubated with AR antibody (Santa Cruz, CA) in 3\% BSA/ PBS overnight at $4^{\circ} \mathrm{C}$. The next day, cells were washed three times in $0.1 \%$ Triton/ PBS and once in PBS and incubated with biotinylated secondary antibody (Dako North America, Carpinteria, CA) for $45 \mathrm{~min}$. Cells were then washed three times in $0.1 \%$ Triton/ PBS and then once again in PBS, followed by an incubation in $0.6 \% \mathrm{H}_{2} \mathrm{O}_{2}$ for $30 \mathrm{~min}$. at room temperature to quench endogenous peroxidase. Cells were then incubated in strep ABC complex (Dako North America) at room temperature for $30 \mathrm{~min}$, washed and incubated with $\mathrm{DAB}$ peroxidase substrate (Vector Laboratories, Youngstown, $\mathrm{OH}$ ) following manufacturer's instructions. Counterstain was performed in dilute Harris hematoxylin (Sigma-Aldrich). Image acquisition was performed as described for immunohistochemistry (see above).

\section{IMMUNOFLUORESCENCE AND ANALYSIS OF NEURITE NETWORK}

$1 \times 10^{5}$ PC12 cells per square centimeter growing on polyD-lysine coated cover slips were differentiated for 5 days in $200 \mathrm{ng} / \mathrm{ml}$ of NGF (Promega), followed by treatment with $75 \mu \mathrm{M}$ of methandienone or 17- $\alpha$-methyltestosterone (Cerilliant) or equal amounts of DME (as the carrier control). Cells were then fixed with $96 \%$ ice-cold ethanol for $10 \mathrm{~min}$. and permeabilized for $5 \mathrm{~min}$. with $0.1 \%$ Triton X-100 in PBS. Cells were blocked in 3\% fetal bovine serum for $30 \mathrm{~min}$., followed by $1 \mathrm{~h}$ incubation in a humidity chamber at room temperature with rabbit polyclonal anti-NF antibody (Cell Signaling Technology, Beverly, MA). The secondary antibody was anti-rabbit IgG conjugated to fluorescein (Sigma Aldrich). The samples were mounted with Vectashield mounting medium containing 4-6-diamino-2phenyl-indole (DAPI, Vector Laboratories). Morphological analysis and quantification of neurite bearing cells were carried out using an Aperio Scanscope (Aperio Technologies, Vista, CA). Ten randomly separated microscopic fields were observed and the proportion of cells with neurites equal to or greater than the length of one cell body were scored positive for neurite outgrowth, with the final result expressed as a percentage of the total number of cells counted. Neurite extension length was also measured for all identified positive neurite bearing cells per field by tracing the longest length neurite using the Neuron J module of Image J software (NIH, Bethesda, MD, version 1.46c). The value of neurite length in pixels (average maximal neurite length per neurite-bearing cell in 10 fields) was calculated and designated as one experiment. All experiments were repeated at least three times on separate days and data are expressed as mean \pm SD.

\section{VITALITY ASSAY}

Cell death was evaluated by staining PC12 cells treated for $48 \mathrm{~h}$ with $75 \mu \mathrm{M}$ methandienone, 17- $\alpha$-methyltestosterone or DME with acridine orange/ethidium bromide mixture (Sigma-Aldrich), each at a concentration of $100 \mu \mathrm{g} / \mathrm{ml}$ in PBS as previously described (Schiera et al., 2007). Cells were observed with a Fluoview FV1000 Confocal Microscope (Olympus).

\section{WESTERN BLOT ANALYSIS}

After the indicated treatment, cells were collected, washed with PBS, and homogenized in lysis buffer (Cell Signaling Technology) supplemented with protease inhibitors $(0.5 \mathrm{mM}$ phenylmethylsulfonyl fluoride, $1 \mu \mathrm{l} / \mathrm{ml}$ aprotinin and leupeptin, Sigma-Aldrich) and phosphatase inhibitors (2 $\mathrm{mM} \mathrm{NaF}$ and $0.5 \mathrm{mM}$ sodium orthovanadate, Sigma-Aldrich). After centrifugation, protein concentrations were measured using the BioRad protein assay (Bio-Rad Hercules, CA). $15 \mu \mathrm{g}$ of protein was loaded onto each lane of $12 \%$ acrylamide-SDS denaturing gels. After electrophoretic separation, samples were electroblotted onto a PVDF membrane (Immobilon P, Millipore Corp., Billerica, MA). The blotting membrane was blocked with 5\% milk and then immunostained with one of the following antibodies: anti-phospho-ERK (Cell Signaling Technology); rabbit polyclonal anti-Hsp90 (Cell Signaling Technology); rabbit polyclonal anti-cleaved caspase 3 (Cell Signaling Technology); rabbit polyclonal anti-PARP (Cell Signaling Technology); anti-GAPDH (Sigma-Aldrich).

\section{RNA EXTRACTION, REVERSE TRANSCRIPTION AND REAL TIME-PCR ANALYSIS}

RNA was extracted from treated and untreated PC12 cells using the TRIZOL reagent (Life Technologies, Grand Island, NY) according to the protocol provided by the manufacturer. After the last step of the protocol, the RNA was air-dried and then dissolved in RNAase free water for quantification by spectrophotometer. $1 \mu \mathrm{g}$ of RNA was used for reverse transcription to cDNA using the AMV reverse-transcriptional system (Promega) in the presence of random hexamers (Invitrogen, Life Technologies). The cDNA was used for quantitative real-time PCR (RT-qPCR) with specific gene primers as follows: Neuritin sense: $5^{\prime}$-gcatctggtgaataatcgctcacg- $3^{\prime}$, anti-sense: $\quad 5^{\prime}$-actgaaggaggcgacgacaatagc- $3^{\prime}$; GAPDH sense: $5^{\prime}$-atcccatcaccatcttccag- $3^{\prime}$, anti-sense: $5^{\prime}$-cctgcttcaccaccttcttg- $3^{\prime}$. The $\mathrm{C}_{\mathrm{T}}$ method was used for data analysis of neuritin mRNA expression, estimated in triplicate samples and normalized to GAPDH expression levels.

\section{STATISTICAL ANALYSIS}

Student's paired $t$ tests were performed on means, and $p$ values calculated: ${ }^{*}, p \leq 0.05 ;^{* *}, p \leq 0.01$.

\section{RESULTS \\ AR IS EXPRESSED IN NEURON-LIKE PC12 CELLS}

The AR, a member of the nuclear receptor superfamily of transcription factors, is capable of binding the principal steroidal androgens testosterone and its metabolite $5 \alpha$-dihydrotestosterone, as well as other AAS, and mediating their effects within the cell (Lee and Chang, 2003). Caraci et al. determined that neurons express this receptor (Caraci et al., 2011), results we confirmed in an immunohistochemical analysis for $\mathrm{AR}$ in rat cerebellum (Figure 1A) and brain stem (Figure 1B). To determine if PC12 cells also express this receptor after differentiation and induction of a neuron-like phenotype, 


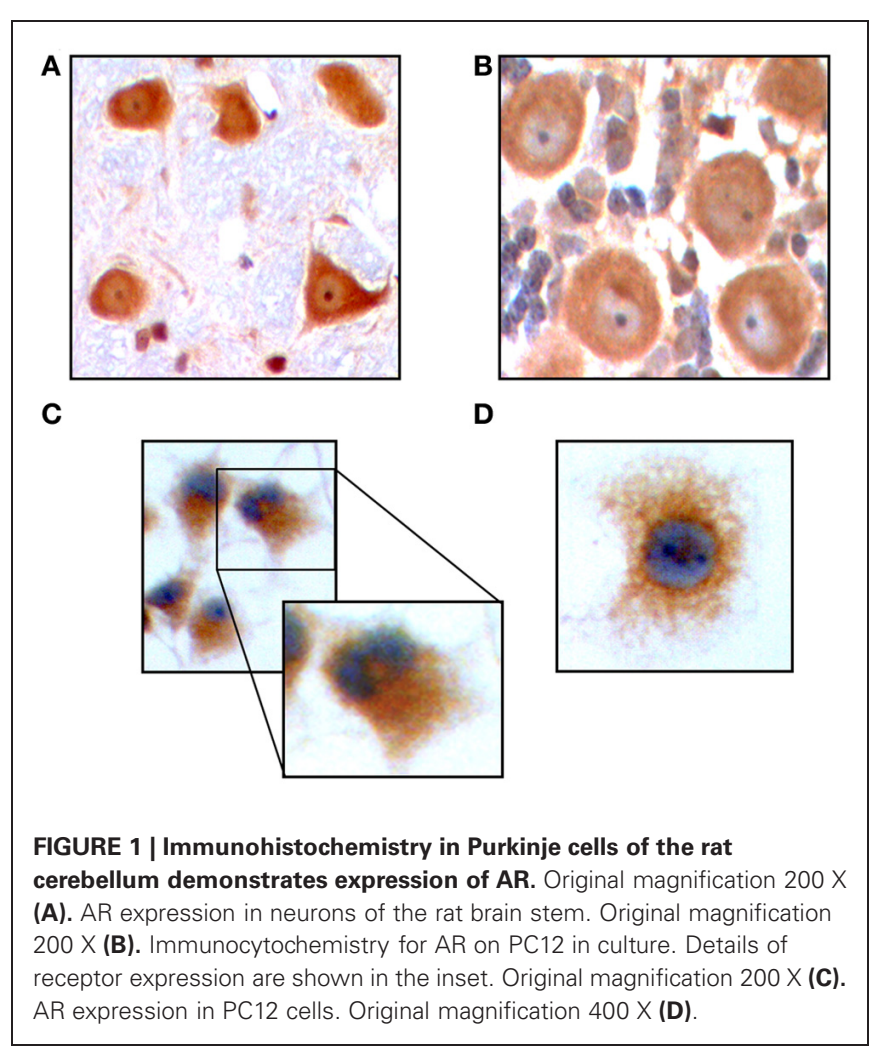

we performed immunocytochemistry for AR on NGF treated PC12 in culture. We observed AR expression in the cytoplasm (Figure 1C), which under higher magnification exhibited a peri-nuclear pattern of expression (Figures 1C, inset, and 1D), contrary to a prior report (Nguyen et al., 2005) but in accordance with others (Gehlhaus et al., 2007; Meyer et al., 2009). These results indicate that PC12 express the receptor for androgens that could be mediating the pathway for AAS to affect cell physiology.

\section{METHANDIENONE AND 17- $\alpha$-METHYLTESTOSTERONE INHIBIT NEURITE NETWORKS}

Neuron cell cultures are a useful system to study potential deleterious effects of different compounds. In this model, alterations in sprout formation and neurite length are used as a determinant of neurotoxicity (Radio and Mundy, 2008). Since culturing PC12 cells in NGF induces formation of neurites, we used this model to determine the effects of methandienone and $17-\alpha$-methyltestosterone on neurons, growing treated cells in control media or media containing 50 or $75 \mu \mathrm{M}$ of these AAS and observing effects on differentiated PC12 neurite outgrowth. While untreated cells exhibited prominent neurite maintenance (Figure 2A, left panel), cells treated with both methandienone (center panel) and 17- $\alpha$-methyltestosterone (right panel) lost this phenotype. Quantification of loss of neurite formation is shown in Figure 2B. Both of these AAS also resulted in dramatic reduction of the total length of all neurites observed, relative to vehicle controls (Figure 2C). Taken together, the results suggest that these AAS can exert toxic effects on neuronal networks, inducing neurite loss and neuronal network damage.

\section{METHANDIENONE AND 17- $\alpha$-METHYLTESTOSTERONE INDUCE DEATH OF PC12 CELLS}

To further determine toxicity, PC12 were grown in $75 \mu \mathrm{M}$ of methandienone and 17- $\alpha$-methyltestosterone and examined for cell death in a vitality assay. In this system, cells are analyzed by immunofluorescence to detect membrane integrity based upon the uptake or exclusion of a dye from the cell. Ethidium bromide (EB) fluoresces red and is only able to pass through the membrane of a dead or dying cell, while acridine orange (AO), which fluoresces green, is a membrane-permeable dye that will stain all cells in the sample. Cells fluorescing yellow are taking up both $\mathrm{EB}$ and $\mathrm{AO}$ and represent an early stage of cell death, with a more orange color indicating a later stage in the process. We observed that most control treated, differentiated PC12 remained vital (Figure 3A, left panel) while cells treated with both methandienone (center panel) and 17- $\alpha$-methyltestosterone (right panel) exhibited prominent increases in indicators of early and late cell death (see insets). When quantified, we observed slightly more cell death in PC12 growing in the presence of 17$\alpha$-methyltestosterone when compared to equal concentrations of methandienone (Figure 3B). These results suggest that both methandienone and $17-\alpha$-methyltestosterone are toxic to neurons, inducing death in treated cells.

\section{AAS INDUCE APOPTOSIS IN PC12}

To confirm that the cell death we observed was apoptosis, and to compare with other AAS to determine if this could be a general mechanism of toxicity for a variety of androgens, we examined by immunoblot for levels of active, phosphorylated ERK, an indicator of cell survival. The MAPK cascade, and in particular ERK, has been shown to be protective in neuronal cell types, allowing them to survive exposure to pro-apoptotic compounds (Karmarkar et al., 2011). Therefore, decreases in phospho-ERK might indicate progression to cell death. We observed decreases in levels of phosphorylated ERK protein following treatment with androsterone, nandrolone, methandienone and 17- $\alpha$-methyltestosterone, compared to controls (Figure 4A, upper panel). We also looked for the appearance of cleaved and hence active caspase 3 as an indicator of apoptosis, cleaved PARP (a caspase target), and cleavage of heat shock protein (Hsp) 90, a chaperone involved in the normal folding of various polypeptides that has been shown to be degraded in cells undergoing apoptosis and that associates with the AR (Chen et al., 2008, 2009), following treatment with the same AAS. We noted upregulation of the active fragment of caspase 3, an indication of activation of the caspase cascade, occurring in response to all AAS used (Figure 4B, upper panel). Additionally, we observed the appearance of cleavage products for PARP and Hsp90 (Figure 4B, middle panels), proteins that are downstream targets of caspases in apoptosis. These results suggest that neuronal cell death may contribute to some of the CNS symptoms observed with long-term use of AAS.

Examining methandienone and 17- $\alpha$-methyltestosterone in more detail, we noted upregulation of the active fragment of caspase 3 occurring in a dose dependent manner following treatment of both of these AAS (Figure 4C, top panels), along with the appearance of cleaved PARP and Hsp90 (Figure 4C, middle panels). GAPDH was used as a loading control for all blots (bottom 
A

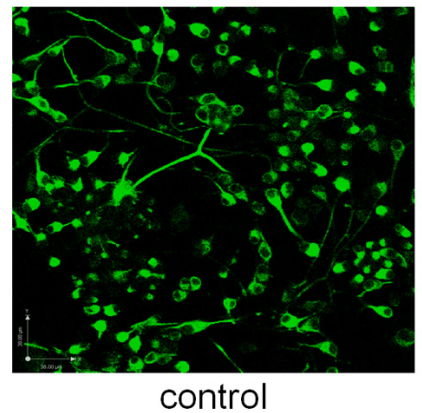

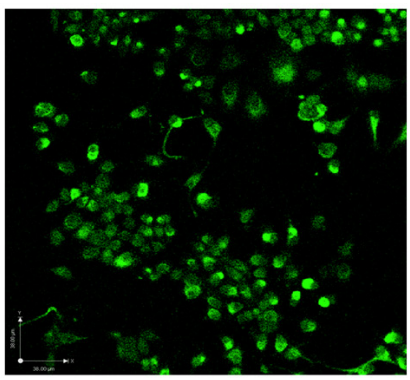

methandienone

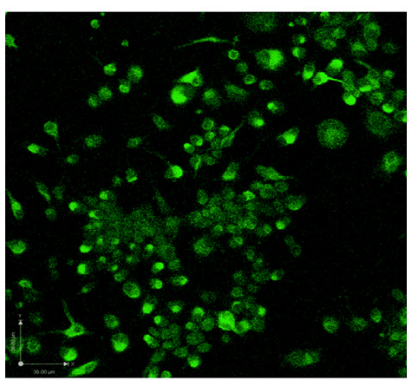

17-a-methyltestosterone
B

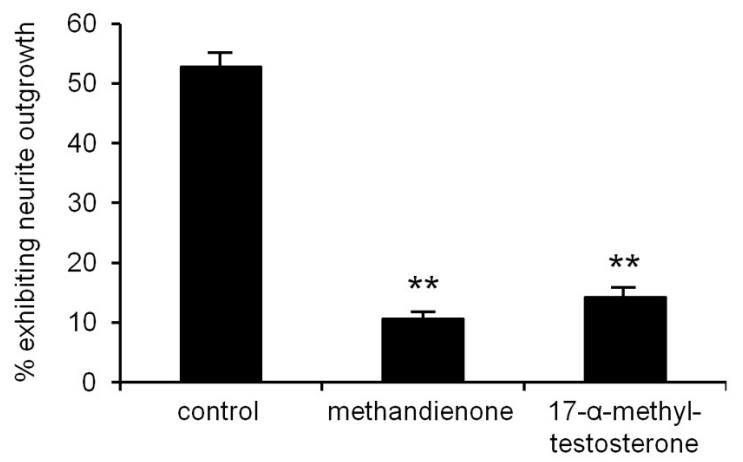

FIGURE 2 | Immunofluorescence for neurofilament to demonstrate neurite outgrowth in PC12 cells differentiated in NGF in tissue culture, either control treated (left panel), treated with $75 \mu \mathrm{M}$ methandienone (center panel) or treated with $75 \mu \mathrm{M}$ of

17- $\alpha$-methyltestosterone (right panel) (A). Quantification of neurite outgrowth in the three conditions shown in (A), as determined by cells exhibiting neurites equal to or greater than the length of one cell body,
C

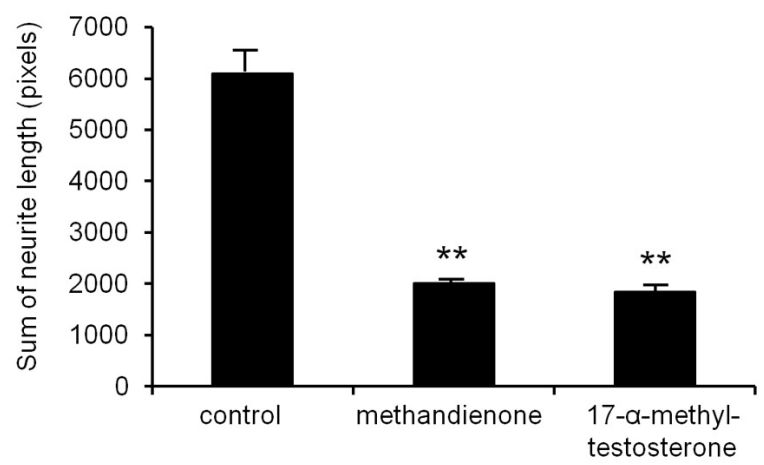

as a percentage of the total number of cells counted (Y-axis).

Experiments were repeated at least three times and data expressed as mean $\pm \mathrm{SD}(* * P \leq 0.01)$. These AAS demonstrate toxic effects on formed neurite networks in differentiated PC12 (B). Average of the sums of neurite length for identified neurite bearing cells in 10 high-power fields (Y-axis). Experiments were repeated at least three times and data expressed as mean \pm SD $\left({ }^{* *} P \leq 0.01\right)$ (C) panels). Similar to the cell death response in the vitality assay, we observed slightly more pronounced indicators of apoptosis in the immunoblot for cells treated with 17- $\alpha$-methyltestosterone compared to methandienone. Taken together, these results suggest that methandienone and $17-\alpha$-methyltestosterone are toxic to neuron-like cells at least in part through activation of apoptosis.

\section{METHANDIENONE AND 17- $\alpha$-METHYLTESTOSTERONE PROMOTE APOPTOSIS THROUGH THE AR}

To determine if apoptosis proceeds through the AR, we treated cells with methandienone and 17- $\alpha$-methyltestosterone but this time in the presence of the anti-androgen hydroxyflutamide (Nguyen et al., 2007). We again observed evidence of cleavage fragments of caspase 3, PARP and Hsp90, but loss of these biochemical indicators of apoptosis when incubated with hydroxyflutamide (Figures 5A,B). This result suggests that the AR mediates the apoptotic effects of these AAS, though further experiments will be necessary to investigate this mechanism in greater detail.

\section{METHANDIENONE AND 17- $\alpha$-METHYLTESTOSTERONE PROMOTE AN INCREASE IN mRNA LEVELS OF NEURITIN}

Neuritin is a neurotrophic factor that plays an important role in neurite growth and survival. It is known to be upregulated in damaged, stressed or ischemic neurons as they attempt to re-establish connectivity following injury (Ujike et al., 2002). Other groups have shown that certain steroids can act through the AR, which we have demonstrated is expressed in differentiated PC12 (Figure 1), to increase neuritin expression (Fargo et al., 2008). Therefore, we looked at neuritin mRNA levels in differentiated PC12 treated with increasing concentrations of methandienone and 17- $\alpha$-methyltestosterone for $24 \mathrm{~h}$. In these conditions, we observed a dose dependent increase in neuritin mRNA levels for both AAS tested with 17- $\alpha$-methyltestosterone, which induced more cell death in the vitality assay, promoting a more dramatic upregulation of neuritin mRNA (Figure 6). These results anticipated suppression of neurite outgrowth and cell death, which were observed after 2 days of treatment, suggesting an adaptive response on the part of the cell to resist AAS toxicity.

\section{DISCUSSION}

There are great challenges in attempting to characterize the potential risks of neurotoxicity for environmental chemicals and pharmacological agents such as AAS. Indeed, among the innumerable commercial compounds available, a relative few have been adequately characterized for their potential effects on human health in general, and fewer still specifically tested for 

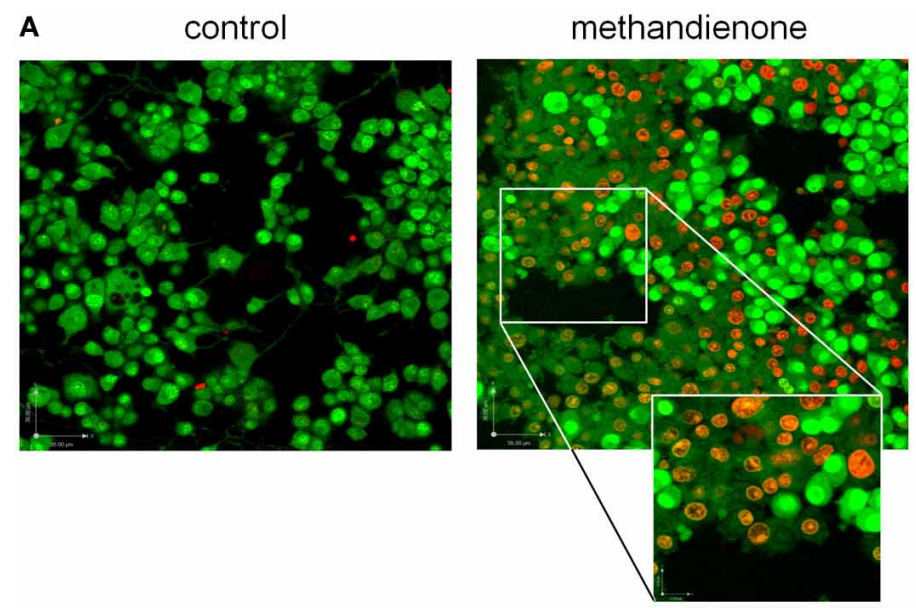

17-a-methyltestosterone

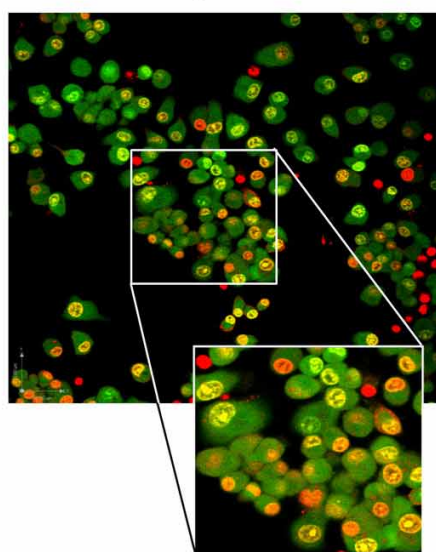

B

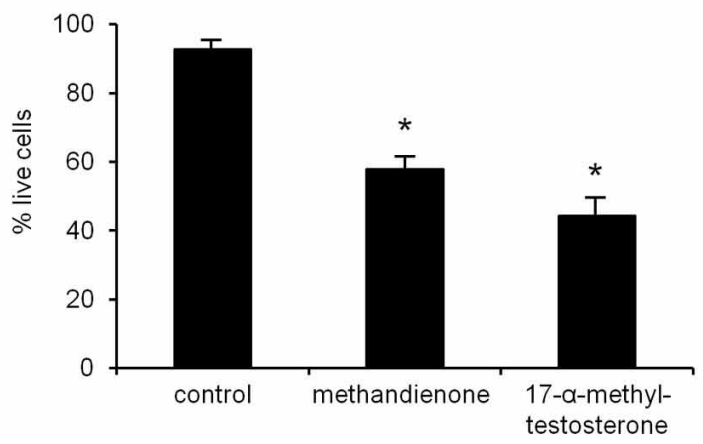

FIGURE 3 | PC12 cells were control treated (left panel) or treated with $75 \mu \mathrm{M}$ methandienone (center panel) or $75 \mu \mathrm{M}$ 17- $\alpha$-methyltestosterone (right panel) for $\mathbf{4 8} \mathrm{h}$ and a vitality assay was performed. Green cells are vital; cells in early cell death are yellow; orange indicates late cell death (A).
Vitality status expressed as percentage of total live cells counted in 10 high power fields ( $Y$-axis) reveals that methandienone and $17-\alpha$-methyltestosterone induce cell death in PC12. Experiments were repeated at least three times and data expressed as mean $\pm \mathrm{SD}(* P \leq 0.05)$ (B). neurotoxicity. It is important to note that the number of studies with rigorous scientific methodology that have derived significant conclusions is small, whereas the intensity of the underground marketing and promotion of most AAS is intense, far exceeding the data supporting their use. At the same time it is important to note that non-hormonal supplements, such as vitamins, amino acids, caffeine and ephedrine often contain anabolic steroids that are not declared on the labels of the products. The most abundant steroids found in these supplements are methandienone and 17- $\alpha$-methyltestosterone.

It has been suggested that tests based on a variety of in vitro assessments may be useful as a screen to identify neurotoxic substances. We employed several cell biological and biochemical techniques to demonstrate that methandienone and 17- $\alpha$-methyltestosterone were damaging neuron-like differentiated PC12 cells through inhibition of neurite networks and apoptosis, suggesting that administration of these AAS for the purpose of enhancing athletic performance could put the user at risk for even more potentially harmful side effects in addition than the better known effects on the endocrine, musculo-skeletal, and reproductive systems.
The development of the CNS involves coordinated gene expression and an ordered initiation of specific cellular events regulating proliferation, differentiation, cell migration, neurite outgrowth, synapse formation, myelination, and programmed cell death. Theoretically, chemically mediated disruption of one or more of these events could potentially impair CNS development or function (Barone et al., 2000). Neurite outgrowth in particular involves many of these processes, including the differentiation of precursor cells to a terminal neuronal phenotype and the initiation and development of broad, sheet-like extensions (lamellipodia) which subsequently condense into short cytoplasmic processes capable of communicating with neighboring cells through synaptogenesis (Craig and Banker, 1994). Alterations in neuronal signaling and synapse formation likely contribute to the outward psychological and behavioral manifestations of steroid use (Penatti et al., 2009, 2011; Oberlander and Henderson, 2012). However, while synapse signaling is one of the first processes to be affected in the premature aging model, for example, neuron degeneration is known to underly many behavior disorders (de Graaf et al., 2013). Therefore, we limited our study to morphology and cell death utilizing the PC12 cell model. PC12s are a well 
A

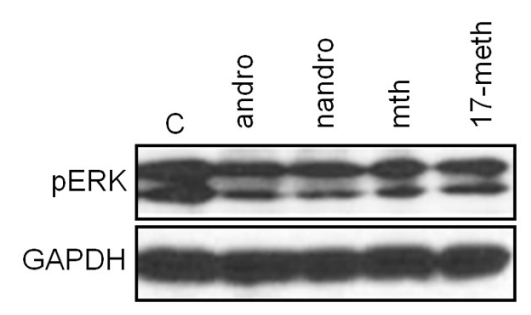

B

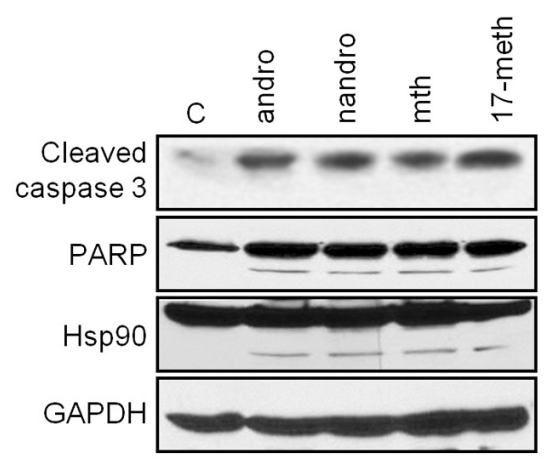

C

concentration
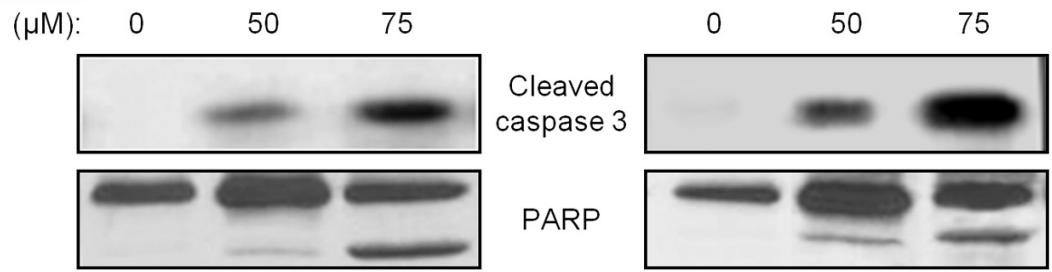

PARP
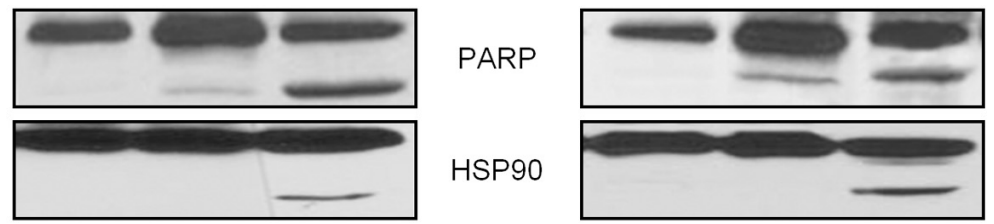

HSP90

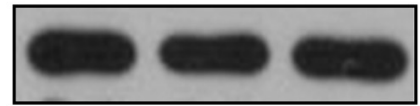

methandienone

GAPDH
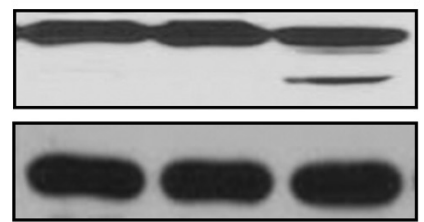

17-a-methyltestosterone

FIGURE 4 | Immunoblots demonstrate decreasing levels of phospho-ERK (top panel) in PC12 treated for $48 \mathrm{~h}$ with $75 \mu \mathrm{M}$ androsterone, nandrolone, methandienone, and 17- $\alpha$-methyltestosterone, compared to control treated cells (A). Immunoblots for caspase 3 (top panel), PARP

(second panel), and Hsp90 (third pane/) in PC12, control treated or treated $48 \mathrm{~h}$ with $75 \mu \mathrm{M}$ androsterone, nandrolone, methandienone, and

$17-\alpha$-methyltestosterone demonstrate increasing levels of the activated fragment of caspase 3 and cleavage of PARP and Hsp90, indications of apoptosis and cell death (B). PC12 were control treated or treated for $48 \mathrm{~h}$ with 50 or $75 \mu \mathrm{M}$ methandienone (left column) or $17-\alpha$-methyltestosterone (right column). Increasing concentrations of these AAS resulted in

appearance of the activated fragment of caspase 3 and cleavage of PARP and Hsp90 in a dose-dependent manner (C). GAPDH was used as the loading control for all blots (bottom panels). characterized in vitro model for evaluation of chemical neurotoxicity because they differentiate into a sympathetic-like neurons and develop extensive neuritic projections following exposure to NGF (Fujita et al., 1989; Vaudry et al., 2002; Radio and Mundy, 2008). Many studies have used PC12 cells to evaluate the effect of environmental chemicals on neurite outgrowth (Chan and Quik, 1993; Das and Barone, 1999; Lein et al., 2000; Crumpton et al., 2001; Parran et al., 2003). Using this model, both neuroprotective (Fargo et al., 2008) and neurodegenerative effects (Radio and Mundy, 2008) of androgens have been described. In the present study, we investigated the effects of supraphysiological amounts of two different AAS, methandienone and 17- $\alpha$-methyltestosterone, and observed dramatic changes in the sympathetic neuron-like PC12 cell line.

The concentrations of steroids used in our experiments are comparable to that used in other studies examining different compounds considered to be performance-enhancing. For example, in Duranti's study, rat L6C5 and mouse C2C12 skeletal muscle cells were treated with up to $20 \mu \mathrm{M}$ of the $\beta_{2}$-adrenergic receptor agonist salmeterol at a concentration of $1 \times 10^{4}$ cells per square centimeter, conditions comparable to our AAS experiments (Duranti et al., 2011). Indeed, 

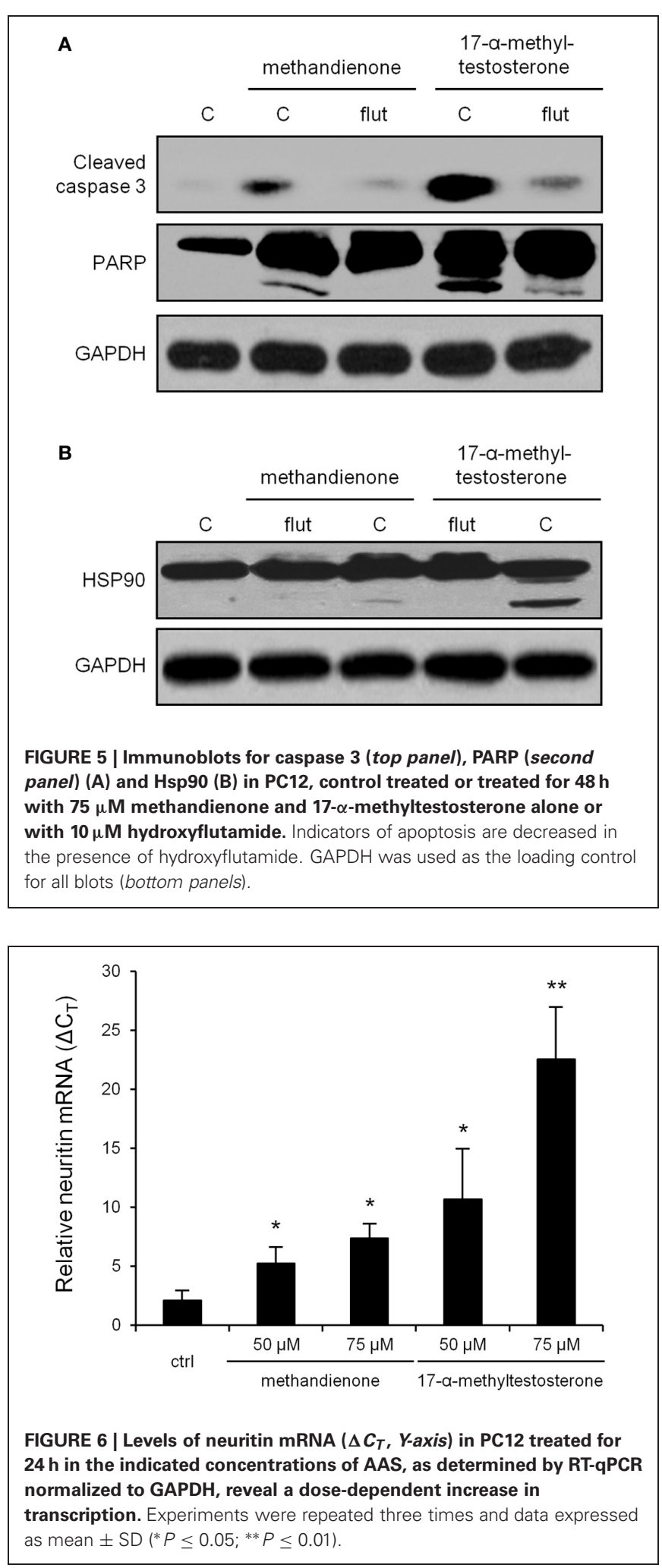

the initial concentration of cells per square centimeter used in our studies is the minimum required to allow neuron-like cells to create a neurite network. Our results demonstrate that methandienone and 17- $\alpha$-methyltestosterone are detrimental to the development of neuron-like characteristics in PC12 cells, and therefore could be considered to have a high risk of neurotoxicity in vivo. As a result, these compounds will likely require further testing.

AAS that previously had been shown to damage neurite networks in PC12 cells have also been shown to activate the apoptotic pathway. Having detected evidence of toxicity in the neurite outgrowth assay, we then wanted to determine if the continued exposure of differentiated PC12 to AAS might induce cell death. Therefore, we examined PC12 cells in a vitality assay and observed evidence of permeability to an acridine orange/ethidium bromide mixture, and hence loss of membrane integrity and cell death, following exposure to methandienone and $17-\alpha$-methyltestosterone, with the latter showing slightly more cell death than the former. To determine the nature of cell death, we investigated phospho-ERK, a marker of ell vitality and survival, and several components of the apoptotic pathway. Phosphorylation of ERK was reduced upon exposure to androsterone, nandrolone, methandienone and $17-\alpha$-methyltestosterone. Caspase 3 is one of the key executioners of apoptosis, engaging in the proteolytic cleavage of many key proteins such as the nuclear enzyme PARP. Indeed, the finding that caspase 3 is expressed in PC12 suggests a role for this protease in PC12 cell death (Haviv et al., 1997). We detected the appearance of the cleaved and hence active form of caspase 3, along with the cleaved form of PARP, in an immunoblot of PC12 exposed to all AAS tested, suggesting that apoptosis might be a generalized response to high concentrations of steroids. When using methandienone and $17-\alpha-$ methyltestosterone, dose dependent increases in these indicators of apoptosis were seen, with a slightly more dramatic response for the same given concentrations of $17-\alpha$-methyltestosterone. Taken together, these results demonstrate that AAS induce apoptosis in neuritized PC12.

We noted that the effects on cells following AAS treatment were delayed, suggesting that these hormones might exert their effects by acting on AR-mediated genomic pathways. Though previous efforts have failed to detect the AR receptor in PC12 cells by RT-PCR (Nguyen et al., 2005), we did in fact demonstrate AR receptor expression in both rat brain (as a control) and in neuronlike PC12 cells growing in culture, supporting the findings of other investigators (Gehlhaus et al., 2007; Meyer et al., 2009) and in a distribution pattern similar to that identified through confocal microscopy in prior publications (Caraci et al., 2011). While androgens can exert rapid non-genomic effects involving induction of second messenger signal transduction cascades, these lipophilic hormones also induce AR dimerization and translocation into the nucleus where the complex engages in direct proteinprotein interaction with transcriptional co-regulators at cognate palindromic response elements to promote the expression of target genes. The presence of AR in PC12 and the delayed responses we observed support a possible genomic influence on cell viability for the AAS (Imperlini et al., 2010). Therefore, to investigate if the mechanism proceeds through AR stimulation, we treated cells with methandienone and 17- $\alpha$-methyltestosterone alone or with the anti-androgen hydroxyflutamide. Loss of indicators of apoptosis in the presence of hydroxyflutamide suggest that AASmediated apoptosis proceeds through the AR and might therefore 
alter gene transcription (Heinlein and Chang, 2002). However, further detailed study is required.

Hsp90 is a molecular chaperone responsible for controlling numerous signaling pathways in the cell (Bishop et al., 2007). It is essentially a protective protein, keeping pro-apoptotic factors in an inert state while simultaneously regulating anti-apoptotic proteins (Lewis et al., 2000). Other studies have shown that cleavage of Hsp90 correlates with activation of apoptosis through both the intrinsic or mitochondrial-mediated death pathway as well as through extrinsic or receptor-mediated pathways (Arya et al., 2007; Chen et al., 2009). Our studies support these conclusions with the observation of the appearance of a cleaved fragment of Hsp90 following treatment of PC12 cells with methandienone and $17-\alpha$-methyltestosterone.

We also observed a dose-dependent increase in neuritin mRNA levels in PC12 cells treated with methandienone and $17-\alpha$-methyltestosterone, which to our knowledge is the first in vitro evidence of androgen-mediated regulation of neuritin mRNA levels in PC12 cells. Neuritin is a gene that regulates androgen-induced (and AR-dependent) neurite outgrowth in motor neurons, usually in response to an injury. In cultured cells, recombinant neuritin protein enhances neurite extension and branching (Naeve et al., 1997). However, unlike in these prior reports, we show that neuritin increases occurred prior to the visible manifestations of loss of neurite formation and cell death. This discrepancy could be attributable to the concentrations of AAS used in our study, which were an attempt to approximate the amounts used by athletes to enhance performance, or differences in cell type and experimental conditions. We regarded increased production of this neurotrophic factor as a response to stress and an attempt at cell survival, as continued exposure to methandienone and 17- $\alpha$-methyltestosterone eventually induced apoptosis. In contrast to our other findings, methandienone elicited a less significant response in this assay (a lower increase in neuritin mRNA) when compared to administration of the same amounts of $17-\alpha$-methyltestosterone. If $17-\alpha$-methyltestosterone truly is more harmful to neuron-like cells than methandienone, as suggested by the vitality assay and apoptosis immunoblots, then

\section{REFERENCES}

Arya, R., Mallik, M., and Lakhotia, S. C. (2007). Heat shock genes - integrating cell survival and death. J. Biosci. 32, 595-610.

Barone, S. Jr., Das, K. P., Lassiter, T. L., and White, L. D. (2000). Vulnerable processes of nervous system development: a review of markers and methods. Neurotoxicology 21, 15-36.

Basaria, S. (2010). Androgen abuse in athletes: detection and consequences. J. Clin. Endocrinol. Metab. 95, 1533-1543.

Basile, J. R., Castilho, R. M., Williams, V. P., and Gutkind, J. S. (2006). Semaphorin 4D provides a link between axon guidance processes and tumor-induced angiogenesis. PNAS 103, 9017-9022.
Bishop, S. C., Burlison, J. A., and Blagg, B. S. (2007). Hsp90: a novel target for the disruption of multiple signaling cascades. Curr. Cancer Drug Targets 7, 369-388.

Caraci, F., Pistara, V., Corsaro, A., Tomasello, F., Giuffrida, M. L., Sortino, M. A., et al. (2011). Neurotoxic properties of the anabolic androgenic steroids nandrolone and methandrostenolone in primary neuronal cultures. J. Neurosci. Res. 89, 592-600.

Carmo, C. A., Goncalves, A. L., Salvadori, D. M., and Maistro, E. L. (2011). Nandrolone androgenic hormone presents genotoxic effects in different cells of mice. J. Appl. Toxicol. 32, 810-814.

Chan, J., and Quik, M. (1993). A role for the nicotinic

it could have promoted higher levels of neuritin transcription as an adaptive response to resist the greater toxicity for this AAS. The differences we observed in PC12 responses to methandienone and $17-\alpha$-methyltestosterone as well as protein expression patterns warrant further investigation.

Here we show that at high concentrations, methandienone and $17-\alpha$-methyltestosterone exert detrimental effects on differentiated PC12 cells expressing AR, including inhibition of neurite network maintenance, induction of cell death through apoptosis and cleavage of the protective chaperone protein Hsp90. Between these two compounds we noted greater cell death and higher neuritin transcription in PC12 in response to $17-\alpha-$ methyltestosterone treatment, supporting the belief that this AAS is the more toxic to neuron-like cells of the two compounds tested. These findings will be pursued in future investigations but currently suggest another potentially harmful physiological effect in the abuse of steroids, that of CNS toxicity.

\section{AUTHORS CONTRIBUTIONS}

John R. Basile provided protocols and support for immunohistochemistry and immunoblot experiments and helped draft the manuscript. Nada O. Binmadi assisted in immunohistochemistry, immunocytochemistry and neurite outgrowth experiments. Hua Zhou and Ying-Hua Yang performed the RT-PCR for neuritin. Antonio Paoli helped plan out experiments and draft the manuscript. Patrizia Proia conceived and designed the study, performed the vitality assays and helped draft the manuscript. All authors read and approved the final manuscript.

\section{ACKNOWLEDGMENTS}

We would like to thank Dr. Dong Wei of the Department of Neural and Pain Sciences at the University of Maryland Dental School for providing the rat brains for AR immunohistochemistry and Dr. Lorena Souza of the National Institutes of Health for assistance with immunofluorescence imaging. Special thanks to Dr. Alessia Gallo and Dr. Gabriella Schiera for their support and critical comments. John R. Basile is supported by the National Cancer Institute, NIH (R01 CA133162).

alpha-bungarotoxin receptor in neurite outgrowth in PC12 cells. Neuroscience 56, 441-451.

Chen, H., Xia, Y., Fang, D., Hawke, D., and Lu, Z. (2009). Caspase-10mediated heat shock protein 90 beta cleavage promotes UVB irradiationinduced cell apoptosis. Mol. Cell Biol. 29, 3657-3664.

Chen, Y., Sawyers, C. L., and Scher, H. I. (2008). Targeting the androgen receptor pathway in prostate cancer. Curr. Opin. Pharmacol. 8, 440-448.

Craig, A. M., and Banker, G. (1994). Neuronal polarity. Annu. Rev. Neurosci. 17, 267-310.

Crumpton, T., Atkins, D. S., Zawia, N. H., and Barone, S. Jr. (2001). Lead exposure in pheochromocytoma (PC12) cells alters neural differentiation and Spl
DNA-binding. Neurotoxicology 22, 49-62.

D’Ascenzo, S., Millimaggi, D., Di Massimo, C., Saccani-Jotti, G., Botre, F., Carta, G., et al. (2007). Detrimental effects of anabolic steroids on human endothelial cells. Toxicol. Lett. 169, 129-136.

Das, K. P., and Barone, S. Jr. (1999). Neuronal differentiation in $\mathrm{PC} 12$ cells is inhibited by chlorpyrifos and its metabolites: is acetylcholinesterase inhibition the site of action? Toxicol. Appl. Pharmacol. 160, 217-230

de Graaf, E. L., Vermeij, W. P., de Waard, M. C., Rijksen, Y., van der Pluijm, I., Hoogenraad, C. C., et al. (2013). Spatio-temporal analysis of molecular determinants of neuronal 
degeneration in the aging mouse cerebellum. Mol. Cell Proteomics. doi: $\quad 10.1074 /$ mcp.M112.024950. [Epub ahead of print].

do Carmo, C. A., Goncalves, A. L., Salvadori, D. M., and Maistro, E. L. (2012). Nandrolone androgenic hormone presents genotoxic effects in different cells of mice. J. Appl. Toxicol. 32, 810-814.

Duranti, G., La Rosa, P., Dimauro, I., Wannenes, F., Bonini, S., Sabatini, S., et al. (2011). Effects of salmeterol on skeletal muscle cells: metabolic and proapoptotic features. Med. Sci. Sports Exerc. 43, 2259-2273.

Fargo, K. N., Alexander, T. D., Tanzer, L., Poletti, A., and Jones, K. J. (2008). Androgen regulates neuritin mRNA levels in an in vivo model of steroid-enhanced peripheral nerve regeneration. J. Neurotrauma 25, 561-566.

Fujita, K., Lazarovici, P., and Guroff, G. (1989). Regulation of the differentiation of PC12 pheochromocytoma cells. Environ. Health Perspect. 80, 127-142.

Gehlhaus, M., Schmitt, N., Volk, B., and Meyer, R. P. (2007). Antiepileptic drugs affect neuronal androgen signaling via a cytochrome P450dependent pathway. J. Pharmacol. Exp. Ther. 322, 550-559.

Greene, L. A., and Rein, G. (1977). Release, storage and uptake of catecholamines by a clonal cell line of nerve growth factor (NGF) responsive pheo-chromocytoma cells. Brain Res. 129, 247-263.

Gruber, A. J., and Pope, H. G. Jr. (2000). Psychiatric and medical effects of anabolic-androgenic steroid use in women. Psychother. Psychosom. 69, 19-26.

Hall, R. C., and Chapman, M. J. (2005). Psychiatric complications of anabolic steroid abuse. Psychosomatics 46, 285-290.

Haviv, R., Lindenboim, L., Li, H., Yuan, J., and Stein, R. (1997). Need for caspases in apoptosis of trophic factordeprived PC12 cells. J. Neurosci. Res. 50, 69-80.

Heinlein, C. A., and Chang, C. (2002). The roles of androgen receptors and androgen-binding proteins in nongenomic androgen actions. Mol. Endocrinol. 16, 2181-2187.

Imperlini, E., Mancini, A., Spaziani, S., Martone, D., Alfieri, A., Gemei, M., et al. (2010). Androgen receptor signaling induced by supraphysiological doses of dihydrotestosterone in human peripheral blood lymphocytes. Proteomics 10, 3165-3175.

Kanayama, G., Boynes, M., Hudson, J. I., Field, A. E., and Pope, H. G. Jr. (2007). Anabolic steroid abuse among teenage girls: an illusory problem? Drug Alcohol Depend. 88, 156-162.

Karmarkar, S. W., Bottum, K. M., Krager, S. L., and Tischkau, S. A. (2011). ERK/MAPK is essential for endogenous neuroprotection in SCN2.2 cells. PLoS ONE 6:e23493. doi: 10.1371/journal.pone.0023493

Kouri, E. M., Pope, H. G. Jr., Katz, D. L., and Oliva, P. (1995). Fat-free mass index in users and nonusers of anabolic-androgenic steroids. Clin. J. Sport Med. 5, 223-228.

Kuhn, C. M. (2002). Anabolic steroids. Recent Prog. Horm. Res. 57, 411-434.

Lee, D. K., and Chang, C. (2003). Molecular communication between androgen receptor and general transcription machinery. J. Steroid Biochem. Mol. Biol. 84, 41-49.

Lein, P., Gallagher, P. J., Amodeo, J., Howie, H., and Roth, J. A. (2000). Manganese induces neurite outgrowth in PC12 cells via upregulation of alpha(v) integrins. Brain Res. $885,220-230$.

Lewis, J., Devin, A., Miller, A., Lin, Y., Rodriguez, Y., Neckers, L., et al. (2000). Disruption of hsp90 function results in degradation of the death domain kinase, receptorinteracting protein (RIP), and blockage of tumor necrosis factorinduced nuclear factor-kappaB activation. J. Biol. Chem. 275, 10519-10526.

Malarkey, W. B., Strauss, R. H., Leizman, D. J., Liggett, M., and Demers, L. M. (1991). Endocrine effects in female weight lifters who self-administer testosterone and anabolic steroids. Am. J. Obstet. Gynecol. 165, 1385-1390.

Meyer, R. P., Gehlhaus, M., Schwab, R., Burck, C., Knoth, R., and Hagemeyer, C. E. (2009). Concordant up-regulation of cytochrome P450 Cyp3a11, testosterone oxidation and androgen receptor expression in mouse brain after xenobiotic treatment. J. Neurochem. 109, 670-681.

Mooradian, A. D., Morley, J. E., and Korenman, S. G. (1987). Biological actions of androgens. Endocr. Rev. 8, $1-28$.

Naeve, G. S., Ramakrishnan, M., Kramer, R., Hevroni, D., Citri, Y., and Theill, L. E. (1997). Neuritin: a gene induced by neural activity and neurotrophins that promotes neuritogenesis. PNAS 94, 2648-2653.

Nguyen, T. V., Yao, M., and Pike, C. J. (2005). Androgens activate mitogen-activated protein kinase signaling: role in neuroprotection. J. Neurochem. 94, 1639-1651.
Nguyen, T. V., Yao, M., and Pike, C. J. (2007). Flutamide and cyproterone acetate exert agonist effects: induction of androgen receptor-dependent neuroprotection. Endocrinology 148, 2936-2943.

Oberlander, J. G., and Henderson, L. P. (2012). The Sturm und Drang of anabolic steroid use: angst, anxiety, and aggression. Trends Neurosci. 35, 382-392.

Orlando, R., Caruso, A., Molinaro, G., Motolese, M., Matrisciano, F., Togna, G., et al. (2007). Nanomolar concentrations of anabolic-androgenic steroids amplify excitotoxic neuronal death in mixed mouse cortical cultures. Brain Res. 1165, 21-29.

Parran, D. K., Barone, S. Jr. and Mundy, W. R. (2003). Methylmercury decreases NGFinduced TrkA autophosphorylation and neurite outgrowth in PC12 cells. Brain Res. Dev. Brain Res. 141, 71-81.

Penatti, C. A., Costine, B. A., Porter, D. M., and Henderson, L. P. (2009). Effects of chronic exposure to an anabolic androgenic steroid cocktail on alpha5-receptor-mediated GABAergic transmission and neural signaling in the forebrain of female mice. Neuroscience 161, 526-537.

Penatti, C. A., Oberlander, J. G., Davis, M. C., Porter, D. M., and Henderson, L. P. (2011). Chronic exposure to anabolic androgenic steroids alters activity and synaptic function in neuroendocrine control regions of the female mouse. Neuropharmacology 61, 653-664.

Radio, N. M., and Mundy, W. R. (2008). Developmental neurotoxicity testing in vitro: models for assessing chemical effects on neurite outgrowth. Neurotoxicology 29, 361-376.

Santamarina, R. D., Besocke, A. G., Romano, L. M., Ioli, P. L., and Gonorazky, S. E. (2008). Ischemic stroke related to anabolic abuse. Clin. Neuropharmacol. 31, 80-85.

Schiera, G., Proia, P., Alberti, C., Mineo, M., Savettieri, G., and Di Liegro, I. (2007). Neurons produce FGF2 and VEGF and secrete them at least in part by shedding extracellular vesicles. J. Cell. Mol. Med. 11, 1384-1394.

Tang, T. S., Slow, E., Lupu, V., Stavrovskaya, I. G., Sugimori, M., Llinas, R., et al. (2005). Disturbed Ca2+ signaling and apoptosis of medium spiny neurons in Huntington's disease. PNAS 102, 2602-2607.

Thiblin, I., Lindquist, O., and Rajs, J. (2000). Cause and manner of death among users of anabolic androgenic steroids. J. Forensic Sci. 45, 16-23.

Tirassa, P., Thiblin, I., Agren, G., Vigneti, E., Aloe, L., and Stenfors, C. (1997). High-dose anabolic androgenic steroids modulate concentrations of nerve growth factor and expression of its low affinity receptor (p75-NGFr) in male rat brain. J. Neurosci. Res. 47, 198-207.

Trifunovic, B., Norton, G. R., Duffield, M. J., Avraam, P., and Woodiwiss, A. J. (1995). An androgenic steroid decreases left ventricular compliance in rats. Am. J. Physiol. 268, H1096-H1105.

Ujike, H., Takaki, M., Kodama, M., and Kuroda, S. (2002). Gene expression related to synaptogenesis, neuritogenesis, and MAP kinase in behavioral sensitization to psychostimulants. Ann. N.Y. Acad. Sci. 965 , 55-67.

Uzych, L. (1992). Anabolic-androgenic steroids and psychiatric-related effects: a review. Can. J. Psychiatry 37, 23-28.

Varshney, A., and Ehrlich, B. E. (2003). Intracellular $\mathrm{Ca} 2+$ signaling and human disease: the hunt begins with Huntington's. Neuron 39, 195-197.

Vaudry, D., Stork, P. J., Lazarovici, P., and Eiden, L. E. (2002). Signaling pathways for PC12 cell differentiation: making the right connections. Science 296, 1648-1649.

Conflict of Interest Statement: The authors declare that the research was conducted in the absence of any commercial or financial relationships that could be construed as a potential conflict of interest.

Received: 12 November 2012; accepted: 23 April 2013; published online: 09 May 2013.

Citation: Basile JR, Binmadi NO, Zhou H, Yang Y-H, Paoli A and Proia P (2013) Supraphysiological doses of performance enhancing anabolic-androgenic steroids exert direct toxic effects on neuron-like cells. Front. Cell. Neurosci. 7:69. doi: 10.3389/fncel.2013.00069

Copyright (c) 2013 Basile, Binmadi, Zhou, Yang, Paoli and Proia. This is an open-access article distributed under the terms of the Creative Commons Attribution License, which permits use, distribution and reproduction in other forums, provided the original authors and source are credited and subject to any copyright notices concerning any thirdparty graphics etc. 